\title{
THERMALLY TREATED COAL TAR-CONTAMINATED SOIL AS A CONCRETE AGGREGATE
}

\author{
Katherine E. Leblanc ${ }^{1}$, John L. Durant ${ }^{2}$, Christopher Swan ${ }^{2}$, Michael J. Weaver ${ }^{3}$, \\ Daniel C. Jansen ${ }^{2}$
}

\begin{abstract}
The current practice of landfilling thermally treated and untreated coal tarcontaminated soil is expensive, and it is a waste of a potentially useful material and landfill space. A less expensive and possibly more practical alternative is to use coal tar-contaminated soil as an aggregate in concrete. Because little work has been done in this area, the present study was undertaken to evaluate the effects of coal tarcontamination and thermal treatment on the physical properties of soil and the strength of concrete containing contaminated soil as an aggregate. Also assessed was the leachability of coal tar constituents (specifically, polycyclic aromatic hydrocarbons (PAHs)) from contaminated soil, concrete containing contaminated soil, and concrete containing thermally-treated contaminated soil.

Mechanical sieve analyses and direct shear tests showed no significant change in grain size distribution or internal friction angle for contaminated and uncontaminated soil treated at $250^{\circ} \mathrm{C}$ and $550^{\circ} \mathrm{C}$. Compressive and splitting tensile strength tests performed on concrete specimens showed a slight decrease in strength with the degree of incorporation of contaminated aggregate. Concrete compressive strength, elastic modulus, and tensile strength also decreased as the aggregate treatment temperature increased, especially at temperatures in excess of $450^{\circ} \mathrm{C}$. However, the strength decreases were small (less than 15\%), and the concrete strength was still within typical values for structural concrete. The leachability tests showed that as treatment temperature was increased, levels of PAHs in the soil significantly decreased. From the leachability tests performed on samples of crushed concrete that contained contaminated soil, it appears that only low molecular weight PAHs (i.e., less than or equal to $166 \mathrm{~g} / \mathrm{mol}$ ) were stabilized by the concrete. The poor stabilization of higher molecular weight PAHs may be an artifact of the sample preparation method which required that the concrete be crushed prior to leaching.
\end{abstract}

\footnotetext{
${ }^{1}$ Graduate Research Assistant, Civil \& Environmental Engineering, Tufts University, Medford, MA 02155

${ }^{2}$ Assistant Professor, Civil \& Environmental Engineering, Tufts University, Medford, MA 02155

${ }^{3}$ Undergraduate Research Assistant, Civil \& Environmental Engineering, Tufts University, Medford, MA 02155
} 


\section{INTRODUCTION}

Between the mid-1800s and the 1960s, manufactured gas plants (MGPs) were widely used in the U.S. to produce gaseous fuel from available coal, coke, oil and other fossil fuels (Hatheway, 1997). A by-product of coal gasification was coal tar, a dense, non-aqueous phase liquid that was often disposed of on-site in wells, pits and lagoons. Coal tar was also introduced into the subsurface environment due to leaks and spills from tanks and piping networks, as well as the dismantling of plants taken out of service (Luthy et al., 1994). The total number of sites in the U.S. contaminated with coal tar is estimated to be more than 32,000 (Hatheway, 1997). Coal tar contamination is of particular concern because it contains a wide range of hazardous chemicals, including polycyclic aromatic hydrocarbons (PAHs), many of which are known or suspected carcinogens (IARC, 1983).

Coal tar-contaminated soil is commonly placed in landfills or treated using thermal processes such as thermal desorption, incineration, and coburning. However, treated soils often contain residual contamination and consequently must be disposed of in solid waste landfills. In a review of 200 coal tar-contaminated sites at which remediation activities have been performed, Owen and Unites (1999) found that $55 \%$ of these sites landfilled contaminated soils and $49 \%$ employed thermal treatment (desorption or coburning). Reusing contaminated soil or treated soil containing residual contamination may be an alternative to disposal in landfills. One possible use for this soil is as an aggregate in concrete. Incorporating coal tarcontaminated soil into concrete may help to stabilize residual contaminants, preventing them from leaching out of the soil. Also, the possibility of marketing soil with residual contamination for use as aggregate in concrete provides a possible financial incentive for remediation.

To date, little work has been done to determine whether thermally treated coal tar-contaminated soil is a suitable concrete aggregate. Several studies have reported relatively high (25\% to $98 \%$ ) stabilization of pure organic compounds (not compounds associated with contaminated soils) in cement (Owens et al., 1996; Faschan et al., 1996; Conner, 1995; Hebatpuria et al., 1999). However, only one study was found in which soils contaminated with organics were incorporated into concrete. In this study it was found that the effective diffusivity of benzene was reduced by as much as five orders of magnitude when contaminated sand was incorporated into concrete (Ezeldin and Vaccari, 1995). Because the investigators did not report on the physical properties of the concrete (i.e., tensile and compressive strength, elastic modulus, etc.), applications for concrete containing contaminated aggregate are not known.

This paper presents an evaluation of some of the physical and chemical properties of thermally treated coal tar-contaminated soil and of concrete incorporating this soil as an aggregate. The specific objectives of this study were to determine the effects of thermal treatment on the physical characteristics of natural and coal tar-contaminated soil, evaluate the strength characteristics of concrete containing thermally treated natural and coal tar-contaminated soil as aggregate, and assess the leachability of PAHs from concrete containing coal tar-contaminated soil as aggregate. 


\section{LABORATORY TEST METHODS}

\section{Soil Mixture Preparation and Geotechnical Testing Procedure}

The soil used in this study was a gap-graded mixture of tan to brown subangular to sub-rounded sand and gravel. This type of soil is typical of many former MGP sites (Luthy et al., 1994). The contaminated soil was prepared by mixing coal tar sludge obtained from a former MGP site in New Bedford, Massachusetts with the air-dried sand and gravel mixture. The final contaminated soil was mixed to contain approximately $3,000 \mathrm{ppm}$ PAHs by weight.

A furnace was used to thermally treat $10 \mathrm{~kg}$ batches of the sand and gravel mixtures. The furnace was preheated to a specified temperature between $250^{\circ} \mathrm{C}$ and $650^{\circ} \mathrm{C}$ before each treatment. The soil was heated for one hour, then promptly removed and spread in a large metal pan to cool. The residence time of one hour was meant to approximate actual practice and temperatures of $250^{\circ} \mathrm{C}$ to $650^{\circ} \mathrm{C}$ represent the range commonly employed during thermal desorption and incineration. However, the laboratory method did not employ mixing by rotary kiln during thermal treatment or cooling by quenching with water, as is commonly performed in thermal treatment processes.

Mechanical sieve tests (ASTM D422) and direct shear tests (ASTM D3080) were performed to characterize the physical properties of the natural and contaminated soil before and after thermal treatment. Two sieve tests were used in order to characterize the full range of particle sizes. A coarse sieve analysis, with sieve sizes between $26.67 \mathrm{~mm}$ and $2 \mathrm{~mm}$ was initially performed. The portion of soil retained on the $2 \mathrm{~mm}$ sieve and in the pan of the coarse sieve analysis was set aside for a fine sieve analysis using sieve sizes between $2 \mathrm{~mm}$ and $0.075 \mathrm{~mm}$.

The direct shear tests were performed using normal loads of $36 \mathrm{~kg}$ and $66 \mathrm{~kg}$ during shear. Based on ASTM specifications and the shear mold dimensions, 6.5 $\mathrm{cm}$ diameter and $5 \mathrm{~cm}$ height, the maximum particle size appropriate for the mold should be $6.5 \mathrm{~mm}$. The soil particle size in this investigation was reduced using a $9.42 \mathrm{~mm}$ sieve. Soil was compacted into the shear mold by tamping three equal lifts each with ten blows using a Harvard miniature compactor ( $290 \mathrm{~g}$ hammer dropped $38 \mathrm{~cm}$ ). The thermally treated soil was also mechanically sieved after direct shear to evaluate particle breakage using the fine sieve analysis.

\section{Concrete Mix Design and Strength Testing Procedure}

The concrete mix design used in this study combined cement, water, coarse aggregate, and sand in the proportions $1: 0.52: 3: 2$, respectively, by weight. Table 1 shows the actual mix proportions for the 13 batches of concrete prepared for this study. From each batch, three $10.2 \mathrm{~cm} \times 20.3 \mathrm{~cm}$ cylinders were prepared for compression tests, and three $10.2 \mathrm{~cm} \mathrm{x} 15.2 \mathrm{~cm}$ cylinders were prepared for splitting tension tests. Elastic modulus, Poisson's ratio, and compressive strength were determined following the procedures of ASTM C369 and ASTM C39. The indirect tensile strengths of the concrete were determined by performing Brazilian splitting tensile tests as per ASTM C496. All specimens were cured in a humid room for 21 days prior to testing. 


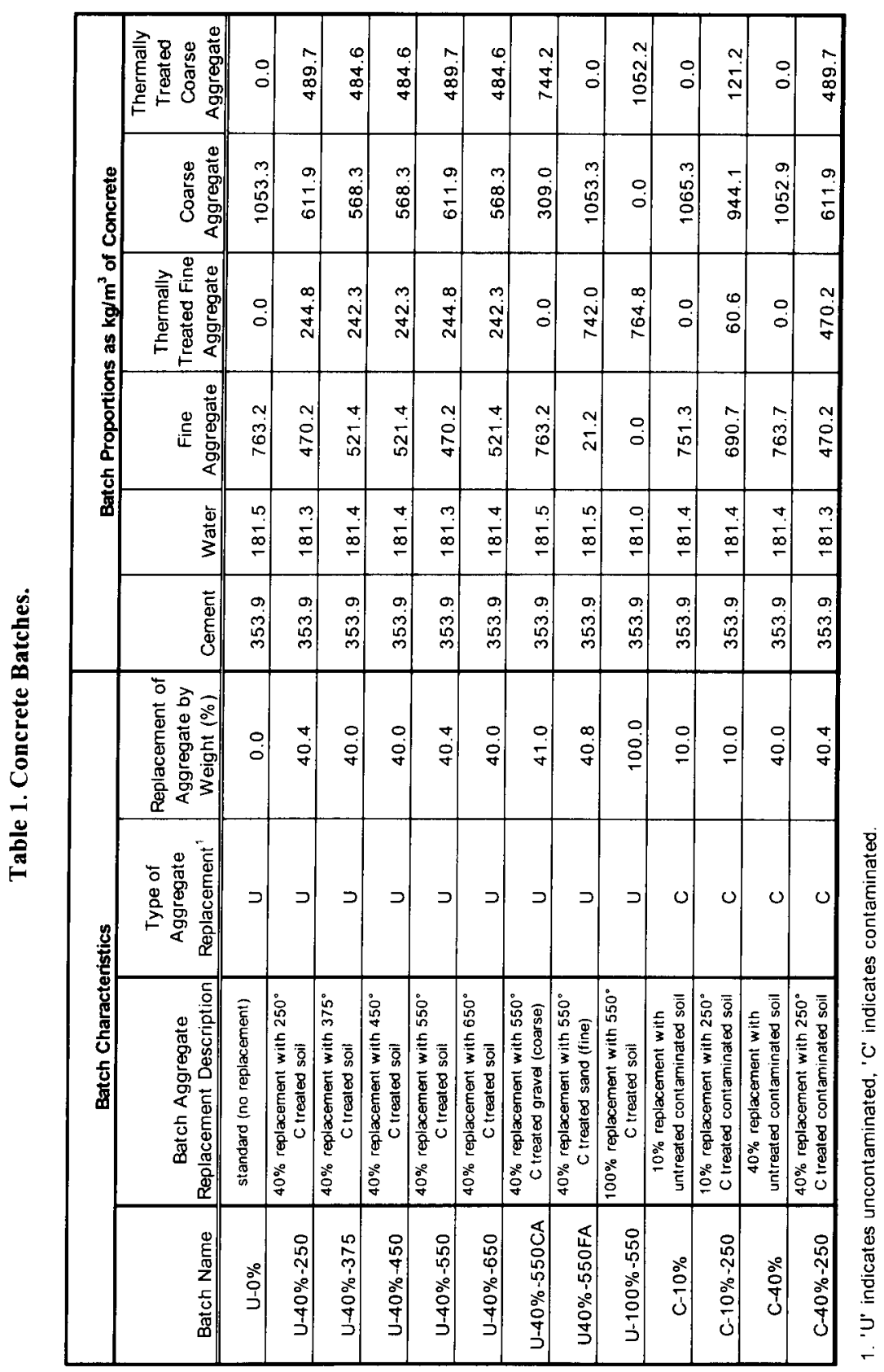




\section{Chemical Analysis of Soil and Concrete}

EPA Method 1311-Toxicity Characteristic Leaching Procedure (TCLP) was used to assess the mobility of selected PAHs from coal tar-contaminated soil and concrete samples. This laboratory procedure is not meant to extract all contaminants from the solids, rather, it is designed to approximate leaching conditions present in the environment given slightly acidic precipitation and groundwater conditions. The TCLP method requires size reduction of the soil and concrete samples so that all particles are smaller than $1 \mathrm{~cm}$. Concrete samples, which were gathered from failed cylinders after strength testing, were crushed using a rubber mallet, then passed through a $1-\mathrm{cm}$ sieve.

Based on preliminary evaluations outlined in the TCLP test, the extraction fluid used for all samples consisted of $5.7 \mathrm{~mL}$ glacial acetic acid and $64.3 \mathrm{~mL} 1 \mathrm{~N}$ $\mathrm{NaOH}$ diluted to 1 liter with distilled water. This solution had a pH of $4.93 \pm 0.05$. For each extraction, $50 \mathrm{~g}$ of solid sample (soil or concrete) was placed in a 1 liter jar with $940 \mathrm{~mL}$ extraction fluid. The jars were then placed in a rotary agitation device and rotated at $30 \mathrm{rpm}$ for 18 hours at ambient temperature $\left(23 \pm 2{ }^{\circ} \mathrm{C}\right)$. Following the extraction procedure, the solid sample was separated from the liquid extract by vacuum filtering through a $0.7 \mu \mathrm{m}$ glass fiber filter. Next, the TCLP extract was liquid-liquid extracted using $500 \mathrm{~mL}$ of methylene chloride (DCM) for 24 hours. The DCM solution was then separated from the water-based TCLP extract solution using a separatory funnel. The Kuderna-Danish method was used to concentrate the DCM to less than $8 \mathrm{~mL}$. Just prior to analysis, this extract was further concentrated by evaporation using pressurized nitrogen gas to less than $1 \mathrm{~mL}$, then approximately $10 \mu \mathrm{L}$ of benzene was added (to provide a solvent with a lower vapor pressure than DCM) and the final solution was concentrated to a volume appropriate for analysis. All glassware was washed with Alconox detergent, then double-rinsed with distilled water, methanol, and DCM.

Concentrations of $15 \mathrm{PAH}$ compounds in the TCLP extract were quantified by gas chromatography (GC) with mass selective detection (MSD) using a selective ion monitoring (SIM) method. The GC/MSD system consisted of a Hewlett Packard (HP) $6890 \mathrm{GC}$ and a HP 5973 MSD. Data acquisition and analysis were conducted using HP MS ChemStation software. The GC system was equipped with a $30 \mathrm{~m}$ HP$55 \%$ phenyl methyl siloxane capillary column that had an inside diameter of 0.25 $\mathrm{mm}$ and a $0.25 \mu \mathrm{m}$ film thickness. The GC oven was programmed as follows: (i) after injection hold for $1.5 \mathrm{~min}$ at $50^{\circ} \mathrm{C}$, (ii) ramp to $310^{\circ} \mathrm{C}$ at $8^{\circ} \mathrm{C} / \mathrm{min}$, and (iii) hold for $10 \mathrm{~min}$ at $310^{\circ} \mathrm{C}$. The flow of the carrier gas (He) was maintained at $1 \mathrm{ml} / \mathrm{min}$; the transfer line temperature was maintained at $280^{\circ} \mathrm{C}$. Samples were injected in 1.4 $\mu \mathrm{L}$ volumes in a split/splitless injector operated in the splitless mode. The mass range scanned was 50 to $450 \mathrm{amu}$ in the electron impact mode $(70 \mathrm{eV})$; the scanning rate was 1.8/s. Quantification of PAH compounds was done by comparing peak areas of compounds detected in extract samples with those of known standards. Calibration curves were developed with authentic standards for 15 compounds. TCLP extract samples and standards were injected in triplicate. 


\section{RESULTS AND DISCUSSION}

\section{Physical Properties of Soil}

After being mixed with coal tar sludge, the formerly tan to brown sand and gravel mixture changed to a dark black-brown and had a distinct odor. After being treated for one hour at $250^{\circ} \mathrm{C}$, the contaminated soil had lightened somewhat in color to a medium brown-gray. This treated soil still had a strong odor that diminished as it cooled. However, the odor never completely abated. The contaminated soil that was treated for one hour at $550^{\circ} \mathrm{C}$ came out of the furnace with a dark pink-brown color and only a slight odor.

Results of the mechanical sieve analyses for all soil groups, as shown in Figure 1 and in Table 2, indicated that thermal treatment had no significant effect on the particle size distribution or distribution parameters of the gap-graded soil.

Results of the direct shear tests performed on densely packed (dry density range of $19.4 \mathrm{kN} / \mathrm{m}^{3}$ to $20.1 \mathrm{kN} / \mathrm{m}^{3}$ ) untreated and thermally treated soils indicated that thermal treatment did not significantly affect shear strength. As shown in Figure 2 , the effective internal soil friction angles ( $\phi^{\prime}$ ) for all five soils were between $39^{\circ}$ and $42^{\circ}$, with an average of $40.6^{\circ}$. Mechanical sieve analysis performed on the thermally treated soils after direct shear testing showed that no significant particle breakage had occurred.

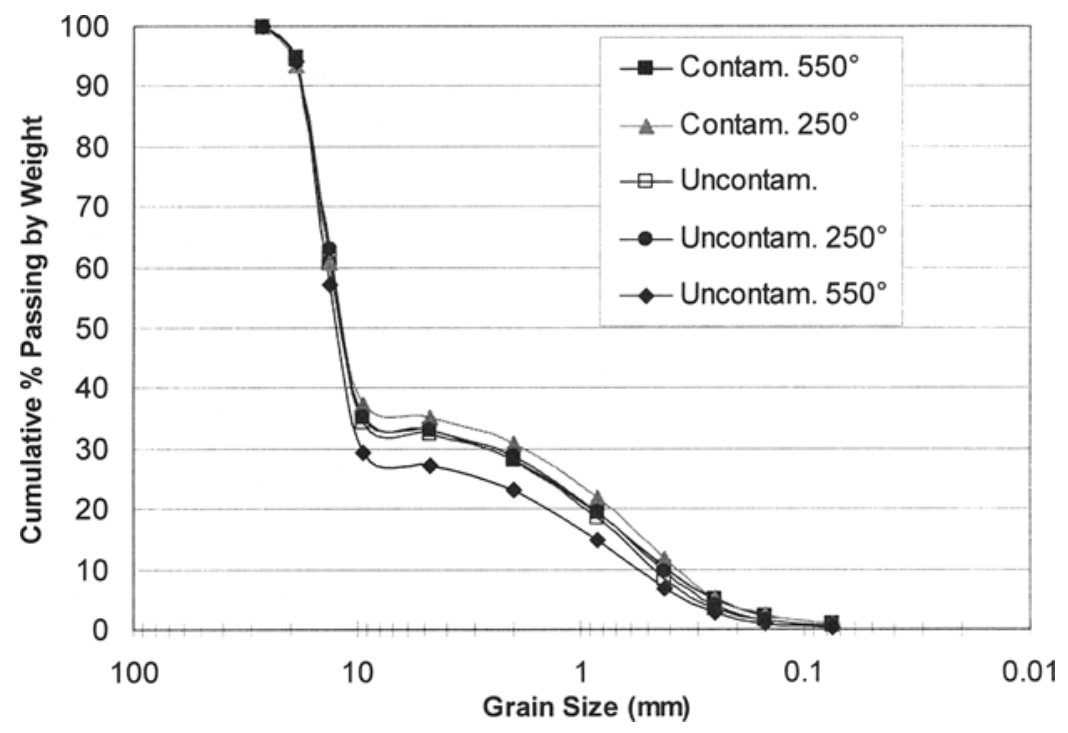

Figure 1. Comparison of Average Grain-Size Distribution of Soil. 
Table 2. Summary of Particle-Size Distribution Parameters.

\begin{tabular}{|c|c|c|}
\hline Soil Type & $\begin{array}{c}\text { Coefficient of } \\
\text { Uniformity, } C_{u}\end{array}$ & $\begin{array}{c}\text { Coefficient of } \\
\text { Gradation, } C_{c}\end{array}$ \\
\hline $\begin{array}{c}\text { Uncontaminated Soil } \\
\text { Gravel Portion } \\
\text { Sand Portion }\end{array}$ & $\begin{array}{l}1.53+/-0.05 \\
3.71+/-0.02\end{array}$ & $\begin{array}{l}0.99+/-0.03 \\
0.98+/-0.04\end{array}$ \\
\hline $\begin{array}{c}\text { Uncontaminated Soil, 250 } \\
\text { Gravel Portion }\end{array}$ & $1.52+/-0.04$ & $1.00+/-0.02$ \\
Sand Portion & $3.73+/-0.02$ & $0.96+/-0.01$ \\
\hline $\begin{array}{c}\text { Uncontaminated Soil, 550 } \\
\text { Gravel Portion }\end{array}$ & $1.53+/-0.01$ & $0.98+/-0.01$ \\
Sand Portion & $3.72+/-0.22$ & $0.98+/-0.06$ \\
\hline Contaminated Soil, 250 $\mathrm{C}$ & $1.59+/-0.01$ & $1.03+/-0.07$ \\
Gravel Portion & $4.07+/-0.50$ & $0.97+/-0.11$ \\
Sand Portion & $1.58+/-0.05$ & $1.01+/-0.04$ \\
Gravel Portion & $4.01+/-0.48$ & $1.03+/-0.03$ \\
\hline Sand Portion & & \\
\hline
\end{tabular}

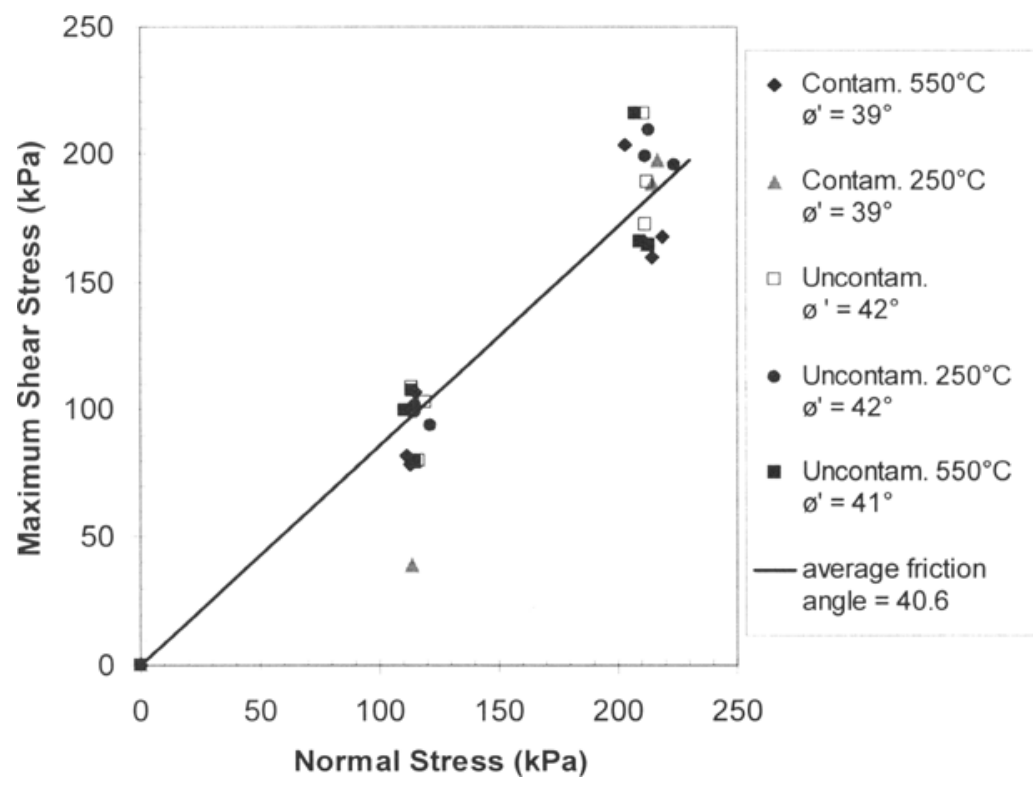

Figure 2. Comparison of Maximum Shear Stress vs. Normal Stress for Soil. 


\section{Physical Properties of Concrete}

Distinct changes in the physical properties of concrete were observed as the treatment temperature of the aggregate was increased. Concrete cylinders containing aggregate treated at temperatures less than $450 \circ \mathrm{C}$ generally failed with the cracks going around the coarse aggregate. In the concrete that contained aggregate treated at higher temperatures, fracturing occurred through the coarse aggregate, causing the aggregate to split into pieces. Results of the compression tests (Figures $3 \mathrm{a}$ and $3 \mathrm{~b}$ ) show little change in compressive strength or elastic modulus with aggregate treatment temperatures up to $450 \circ \mathrm{C}$. However, decreases in both compressive strength and elastic modulus were apparent in concrete samples incorporating aggregate treated at temperatures greater than $450 \circ \mathrm{C}$. At an aggregate treatment temperature of $650 \circ \mathrm{C}$, compressive strength and elastic modulus were decreased by $9 \%$ and $14 \%$, respectively, as compared to concrete containing untreated aggregate. Results of split cylinder tests on uncontaminated soil, shown in Figure 4, demonstrate a general decrease in splitting tensile strength as the treatment temperature of replaced aggregate is increased. The splitting tensile strength decreased on average by approximately $1.3 \%$ per $100 \circ \mathrm{C}$ increment in treatment temperature. It is expected that at treatment temperatures greater than $250 \circ \mathrm{C}$, the splitting tensile strength of concrete containing contaminated soil would likewise decrease.

The results also show that when the amount of untreated contaminated aggregate substitution is increased from $10 \%$ to $40 \%$, the splitting tensile strength of the concrete decreases. This is most likely due to coal tar coating the surface of aggregate and preventing bonds from forming between aggregate and cement. At a treatment temperature of $250 \circ \mathrm{C}$, the splitting tensile strengths of concrete containing contaminated aggregate are similar to concrete containing uncontaminated aggregate, suggesting that the negative effects regarding aggregate-cement bonds have been eliminated by thermal treatment.

Although changes in strength parameters of concrete due to thermal treatment of aggregate are clear, the small decreases in compressive strength, elastic modulus and splitting tensile strength may not be critical, as even the reduced values remain within typical range for structural concrete.

\section{Chemical Analysis of Soil TCLP Extracts}

After the 18 hour extraction process, the uncontaminated soil, untreated contaminated soil, and $250 \circ \mathrm{C}$-treated contaminated soil TCLP solutions appeared cloudy from the tan-colored fines that remained in suspension after agitation was completed. The $550 \circ \mathrm{C}$-treated contaminated soil TCLP solution was completely opaque and dark brown, indicating a greater degree of suspended fine particles. The $\mathrm{pH}$ of the TCLP extract was $4.93 \pm 0.05$ both before and after extraction.

The results in Table 3 show that, as expected, the amounts of leachable PAHs in soil decreased as treatment temperature increased. Compared to the TCLP extract of the untreated contaminated soil, the total amount of PAHs in the extracts of the soils treated at $250 \circ \mathrm{C}$ and $550 \circ \mathrm{C}$ decreased by $73 \%$ and $98 \%$, respectively. For the $250 \circ$ C-treated soil extract, the concentrations of pyrene, benz(a)anthracene, chrysene, benzo(b)fluoranthene and benzo(a)pyrene were not significantly different 

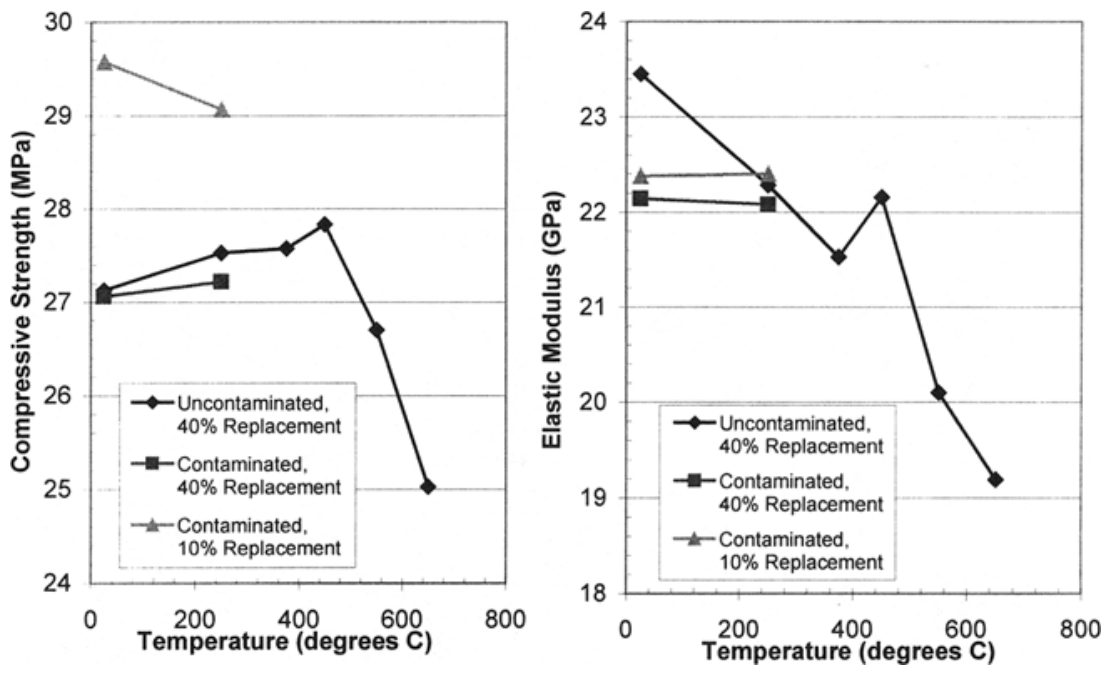

Figure 3. a) Temperature of Aggregate Treatment vs. Compressive Strength and b) Temperature of Aggregate Treatment Elastic Modulus of Concrete

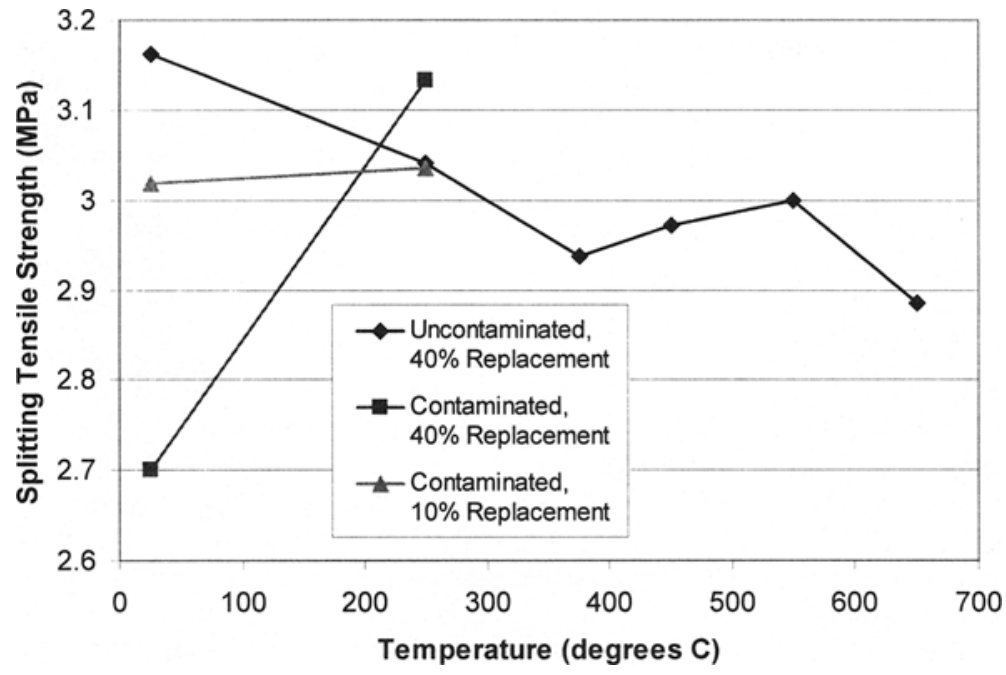

Figure 4. Temperature of Soil Treatment versus Tensile Strength of Concrete Specimens. 


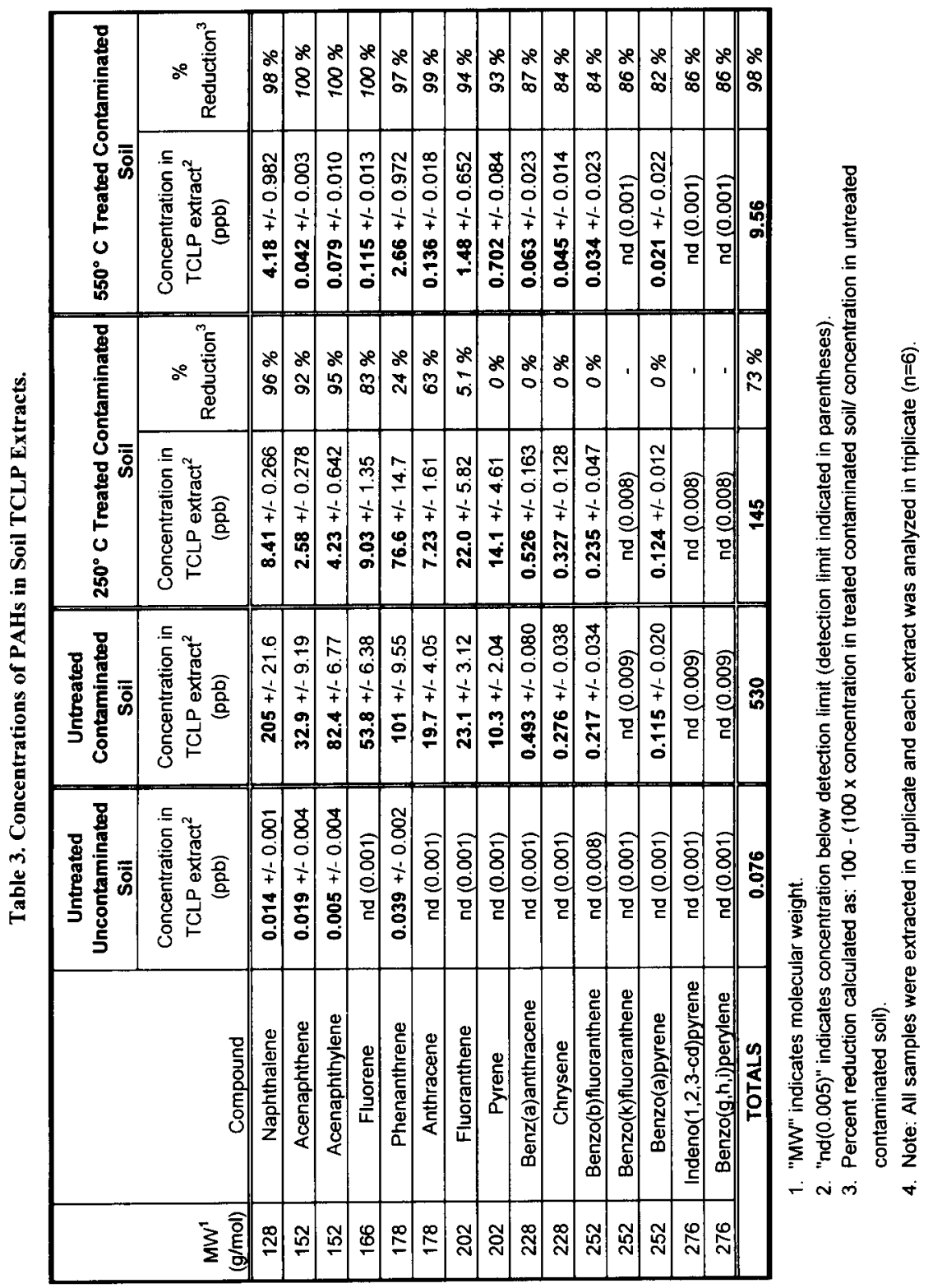


than those in the untreated soil extract. In fact, for these compounds, the concentrations in $250^{\circ} \mathrm{C}$ treated soil actually exceeded the concentrations in untreated soil. While these differences in concentrations are not statistically significant, the results indicate that at this temperature there was no net removal of higher molecular weight (i.e., greater than $202 \mathrm{~g} / \mathrm{mol}$ ) PAHs. In the $550^{\circ} \mathrm{C}$ - treated soil extract, the removal efficiencies for lower molecular weight PAHs (i.e., less than or equal to $202 \mathrm{~g} / \mathrm{mol}$ ) were greater than $90 \%$, while for higher molecular weight PAHs the removal efficiencies were greater than $80 \%$.

Factors related to how the thermal treatment was accomplished may explain the lower than expected reductions of PAHs. In this study we used a furnace to perform thermal treatment. The soil samples were placed in bowls inside the furnace for one hour at the desired temperature and then removed to cool. In rotary kiln incinerators, used widely in treating contaminated soils, the contaminated soil is constantly mixed by the rotation of the furnace bed. These conditions greatly favor the volatilization and thermal destruction of PAHs in contaminated soils. It is expected that the reduction efficiencies achieved with a rotary kiln would be significantly higher than what was observed under laboratory conditions.

\section{Chemical Analysis of Concrete TCLP Extracts}

After the 18 hour extraction process, TCLP extracts of the concrete samples appeared opaque and gray in color. Upon examining the filtered solids, it was apparent that the concrete chunks had partially disintegrated, leaving behind loose aggregate and fine cement powder. During extraction, the $\mathrm{pH}$ of the extraction fluid changed from $4.93(t=0)$ to $12.13(t=18 \mathrm{hrs})$ due to the alkaline nature of the concrete.

The concentrations of PAHs measured in the concrete TCLP extracts are shown in Table 4. The results for the $\mathrm{C} 10 \%$ and $\mathrm{C} 40 \%$ concrete indicate that incorporation of contaminated soil into concrete caused some stabilization of PAHs. The total concentration of 15 PAHs measured in the $\mathrm{C} 10 \%$ and $\mathrm{C} 40 \%$ extracts was on average $82 \%$ lower than what was expected had no stabilization occurred. Stabilization appeared to be greatest for the PAHs with molecular weights less than or equal to $178 \mathrm{~g} / \mathrm{mol}$. For higher molecular weight PAHs, the measured concentrations actually exceeded expected concentrations based on the mass of contaminated aggregate added to the concrete. While these increases in concentrations are not statistically significant, the results provide clear indication that the higher molecular weight PAHs were not well stabilized in the concrete.

Results similar to these were obtained for the concrete containing soil treated at $250{ }^{\circ} \mathrm{C}$. Lower molecular weight PAHs were relatively well stabilized in both C10\%-250 and C40\%-250 concrete, while the higher molecular weight compounds were not. In contrast to the results for $\mathrm{C} 10 \%$ and $\mathrm{C} 40 \%$ concrete, the total concentrations of 15 PAHs measured in the C10\%-250 and C40\%-250 extracts were comparable to what was expected in the absence of stabilization. Driven largely by high levels of phenanthrene, fluoranthene, and pyrene, the total concentration of 15 PAHs measured in the $\mathrm{C10} \%-250$ extract was actually somewhat higher than expected in the absence of stabilization. Similarly, the total PAH concentration for the C40\%-250 extract was only slightly lower than what was expected in the absence of stabilization. It is not clear why the higher molecular weight PAH were not better 


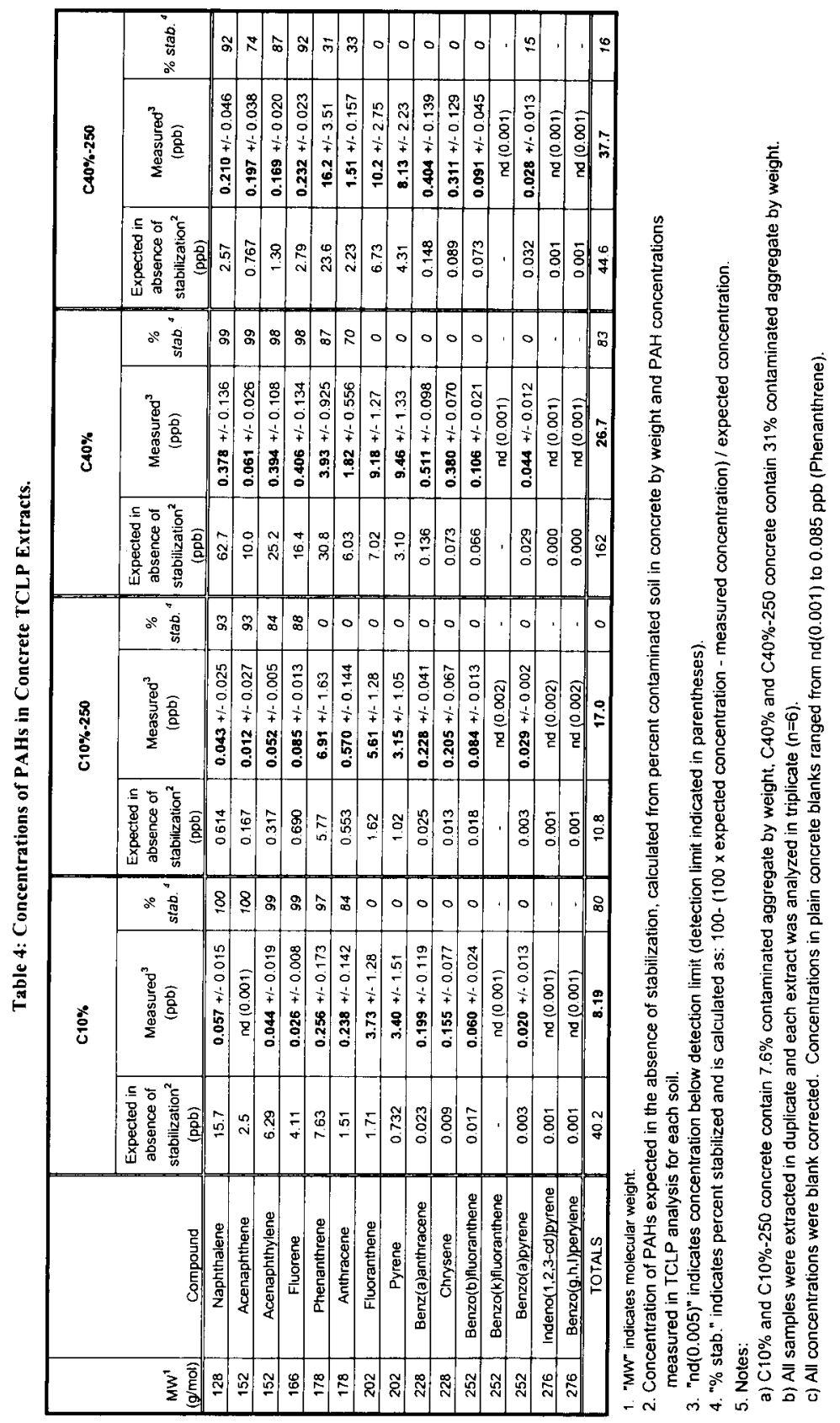


stabilized in the concrete. It is possible that by crushing the concrete and subjecting the pieces to rotary extraction, which caused further particle breakage, the surface area of the concrete was sufficiently increased to allow near complete dissolution of higher molecular weight PAHs. But if this were the case, it would also be expected that less than $166 \mathrm{~g} / \mathrm{mol}$ PAHs should also have been poorly stabilized. That our results indicate otherwise may reflect unaccounted losses (rather than stabilization) of lower molecular weight (less than $166 \mathrm{~g} / \mathrm{mol}$ ) PAHs during concrete preparation, curing, TCLP extraction, or chemical analysis.

Additional factors that may have affected the results have to do with the TCLP extraction methods used. Prior to extraction, it was necessary to break the concrete into small pieces, and this often resulted in the fracture of gravel-sized aggregate. As a result, the TCLP extracts of the concrete represent leachable PAHs on both the sand and gravel whereas the TCLP extracts of the soil represent leachable PAHs only on particles passing a $1 \mathrm{~cm}$ sieve. Since smaller soil particles have a greater specific surface area than gravel sized particles, a given amount of contaminated sand would be expected to contain a greater mass of PAHs than the same amount of contaminated sand and gravel. Consequently, this method may have led to an overestimate of the expected concentrations and percent stabilization of lower molecular weight PAHs in concrete. Also, during rotary extraction, the samples of concrete partially disintegrated, which may have caused fine particles to remain in TCLP extract even after filtration through a $0.7 \mu \mathrm{m}$ glass fiber filter. Since PAHs tend to sorb on to particulate matter, this may have resulted in increased concentrations of higher molecular weight PAHs in the filtered extract. It is likely that the degree of concrete disintegration and PAH leachability would be decreased if the concrete was not crushed prior to TCLP extraction.

\section{SUMMARY}

The results of this study show that thermally treated coal tar-contaminated soil may be useful as a concrete aggregate. Geotechnical tests indicated that no significant changes in shear strength or grain size distribution occur for soils subjected to thermal treatment up to temperatures of $550^{\circ} \mathrm{C}$. Decreases in concrete strength parameters associated with incorporation of contaminated and thermally treated aggregate were small, and in all cases, concrete strength remained within typical values for structural concrete. Treating aggregate at $250^{\circ} \mathrm{C}$ appeared to eliminate the strength changes associated with coal tar contamination, and at treatment temperatures as high as $650^{\circ} \mathrm{C}$ strength decreases did not exceed $10 \%$. Leachability results suggest that incorporating coal tar-contaminated soil into concrete may stabilize PAHs with molecular weights less than or equal to $166 \mathrm{~g} / \mathrm{mol}$. However, additional work is needed to better characterize this stabilization and to quantify losses of lower molecular weight PAHs (e.g. due to volatilization) during TCLP extraction and from the concrete during mixing and curing. The relatively high leachability of PAHs with molecular weight greater than or equal to $166 \mathrm{~g} / \mathrm{mol}$ may be a result of the leaching method used. 


\section{REFERENCES}

Conner, J. R. (1995), "Recent Findings on Immobilization of Organics as Measured by Total Constituent Analysis," Waste Management, Vol. 15 Nos. 5/6, pp. 359-369.

Ezeldin, H. S. and Vaccari, D. A. (1995), "Emissions from Contaminated Soil Fixed in Concrete," GeoEnvironment 2000, Vol. 1, Geotechnical Special Publication No. 46, pp. 406-420.

Faschan, A., Tittlebaum, M. and Cartledge, F. (1996), "A Model to Predict the TCLP Leaching of Solidified Organic Wastes," Hazardous Wastes and Hazardous Materials, Vol. 13 No. 3, pp. 333-350.

Hatheway, A. W. (1997), "Manufactured Gas Plants: Yesterday's Pride, Today's Liability," Civil Engineering, November 1997, pp.38-41.

Hebatpuria, V., Arafat, H. A., Bishop, P. L. and Pinto, N. G. (1999), "Leaching Behavior of Selected Aromatics in Cement-Based Solidification/ Stabilization under Different Leaching Tests," Environmental Engineering Science, Vol. 16 No. 6, pp. 451-463.

International Agency for Research on Cancer (IARC). (1983), "Polynuclear Aromatic Compounds, Part 1, Chemical, Environmental and Experimental Data"; Lyon, France: Vol. 32.

Luthy, R. G., Dzombak, D.A., Peters, C.A., Roy, S. B., Ramaswami, A., Nakles, D.V. and Nott, B.R. (1994), "Remediating Tar-Contaminated Soils at Manufactured Gas Plant Sites," Environmental Science \& Technology, Vol. 28, No. 6, pp. 266-276.

Owen, S. B. and Unites, D.F. (1999), "A Survey of MGP Site Remedial Technologies: It's Excavation and Landfill for Most MGP Sites," The GEI MGP Reporter, March 1999, pp. 1,3.

(http://www.geiconsultants.com/newsletters/reporter.html)

Owens, J.W. and Stewart, S. (1996), "Cement Binders for Organic Waste," Magazine of Concrete Research, March 1996, pp. 37-44. 